Quim. Nova, Vol. 25, No. 3, 396-405, 2002.

\title{
ESPECTROMETRIA DE ABSORÇÃO ATÔMICA COM ATOMIZAÇÃO ELETROTÉRMICA EM FILAMENTO DE TUNGSTÊNIO. UMA RE-VISÃO CRÍTICA
}

\author{
Anderson Schwingel Ribeiro, Marco Aurélio Zezzi Arruda e Solange Cadore* \\ Instituto de Química, Universidade Estadual de Campinas, CP 6154, 13083-970 Campinas - SP
}

Recebido em 3/1/01; aceito em 8/8/01

\begin{abstract}
ELECTROTHERMAL ATOMIC ABSORPTION SPECTROMETRY WITH TUNGSTEN COIL. A CRITICAL RE-VIEW. In this review it is presented some aspects of electrothermal atomic absorption spectrometry with tungsten coil (ETAW-AAS) since its beginning until the present days as well as the perspectives for this technique. Some aspects concerning its development and theoretical concepts are discussed. The analytical figures of merit such as limit of detection (LD), characteristic mass $\left(\mathrm{m}_{0}\right)$, relative standard deviation (RSD), accuracy and precision are evaluated, compared and discussed considering published works. It is also evaluated its advantages, applications, limitations and instrumental development. The use of diode laser as radiation source and its perspectives to ETAW are also discussed.
\end{abstract}

Keywords: electrothermal atomic absorption spectrometry; tungsten coil; analytical characteristics.

\section{INTRODUÇÃO}

A espectrometria de absorção atômica (AAS) revolucionou a determinação de elementos metálicos durante as décadas de 1950 e 1960. Esta técnica, que consiste na introdução de uma solução da amostra num atomizador, através de um sistema de nebulização, foi desenvolvida e proposta no início dos anos 50 por Alan Walsh, que publicou os resultados de seu trabalho na revista Spectrochimica Acta, em 1955, sob o título: The application of atomic absorption spectra to chemical analysis ${ }^{1}$. No princípio, houve certa descrença entre os espectroscopistas da época que, até então, só utilizavam o espectro de emissão atômica para as análises químicas. Entretanto, a utilização do espectro de absorção atômica, uma nova técnica que prometia ser tão promissora, segundo o seu criador, chamou a atenção do russo Boris V. L'vov, que não só confirmou a validade dos experimentos realizados por Walsh, mas acreditou na potencialidade da técnica e dedicou-se com afinco na sua utilização e aperfeiçoamento.

O conceito de atomização eletrotérmica foi introduzido por L'vov em 1959, mas tornou-se bem conhecido a partir de uma publicação de $1961^{2}$. Neste trabalho, a amostra era depositada na superfície de um eletrodo móvel de grafite e, em seguida, introduzida em um tubo de grafite revestido com uma folha de tântalo, o qual era aquecido eletricamente. Este sistema possibilitava a atomização da amostra numa única etapa, fornecendo uma nuvem atômica mais concentrada e, dessa maneira, uma melhor sensibilidade era alcançada, com menor consumo da amostra.

A AAS parece ser, à primeira vista, uma técnica bastante simples se comparada com outras técnicas de espectrometria atômica. Ainda hoje, após 45 anos da primeira publicação, é uma das técnicas mais utilizadas na determinação de baixas concentrações de elementos, podendo estar associada a sistemas de análise em fluxo (FA). Além disso, a utilização de diferentes formas de atomização (chama, atomização eletrotérmica, etc.), permite a especiação e a amostragem sólida ou suspensão ("slurry") ${ }^{3}$.

A técnica de espectrometria de absorção atômica com atomização eletrotérmica (ETAAS), apesar de ser geralmente monoelementar, é adequada para a determinação de baixas concentrações de metais e

*e-mail: cadore@iqm.unicamp.br semimetais, apresentando alta sensibilidade, uma vez que a alíquota da amostra colocada dentro do forno é atomizada em um curto período de tempo, e o tempo de residência média dos átomos no caminho óptico é elevado (1 segundo ou mais) ${ }^{4}$. Além disso, a técnica apresenta boa seletividade, requer pequenos volumes de amostra e possui limites de detecção, para a maioria dos elementos, em concentrações da ordem de $n g \mathrm{~L}^{-1}$ e $\mu \mathrm{g} \mathrm{L}^{-1}$.

Entretanto, apesar das vantagens que a ETAAS propicia, a etapa de atomização para a maior parte dos elementos só é alcançada a temperaturas que variam de 2700 a $3000{ }^{\circ} \mathrm{C}$, sendo necessária uma potência elétrica $\geq 2 \mathrm{KW}$, o que resulta num alto consumo de energia elétrica. Além disso, o custo de cada tubo de grafite é alto devido a vários fatores, dentre os quais destacam-se: (a) recobrimento do tubo com grafite pirolítico, o qual se faz necessário para minimizar a porosidade e aumentar a resistência por ataques químicos, a fim de diminuir os efeitos de memória e/ou interferências provenientes da formação de carbetos; (b) a vida útil do tubo de grafite; (c) a necessidade de alto grau de pureza do grafite e (d) a produção ser destinada a uma demanda não muito elevada ${ }^{5}$.

Uma alternativa de menor custo vem sendo proposta, na qual são utilizados atomizadores eletrotérmicos com filamento de tungstênio (ETAW), para a determinação de diversos elementos, em substituição ao tubo de grafite. Estes dois sistemas apresentam algumas características muito semelhantes e outras, bastante diversas.

Entre as vantagens da técnica de ETAW pode-se destacar ${ }^{5-9}$ : (a) o baixo custo de cada filamento de tungstênio, pois o mesmo é utilizado em retroprojetores e projetores fotográficos, resultando numa alta demanda de fabricação; (b) o baixo consumo de energia elétrica, da ordem de 150 ou $250 \mathrm{~W}$ (o filamento opera a $15 \mathrm{~V}$ e $10 \mathrm{~A}$ ou $25 \mathrm{~V}$ e $10 \mathrm{~A}$, respectivamente); (c) alcança temperaturas de aproximadamente $3200{ }^{\circ} \mathrm{C}$, variando de acordo com a voltagem aplicada; (d) não tem efeito de memória, pois a superfície do filamento não é porosa, (e) não necessita de sistema de refrigeração, (f) dispensa o uso de amostrador automático, devido à tensão superficial do tungstênio e (g) não ocorre a formação de carbetos refratários, o que possibilita a determinação de alguns elementos que formam carbetos em superfícies de grafite (como os lantanídeos).

Os fornos de filamento são, em geral, adaptados a equipamentos comerciais que fazem uso de corretores de fundo contínuo, como as lâmpadas de deutério, uma vez que a adaptação aos equipamentos 
que empregam corretores de fundo baseados no efeito Zeeman não é uma alternativa viável.

Durante a etapa de atomização, o fluxo do gás não é interrompido nos sistemas de ETAW-AAS atuais, para evitar queimas do filamento. Entretanto, se fosse desenvolvido um sistema que possibilitasse a parada de gás nos fornos com filamento, durante a etapa de atomização, o tempo de residência do analito no caminho óptico poderia ser aumentado e, possivelmente, uma maior isotermicidade poderia ser alcançada. Apesar de não serem isotérmicos, os fornos de filamento de tungstênio atualmente empregados têm uma aplicabilidade bastante grande se o analista souber preparar adequadamente as amostras a serem empregadas nas análises. Em sistemas mais isotérmicos, muitas interferências que podem ocorrer na fase gasosa podem ser minimizadas ou mesmo eliminadas e, dessa maneira, as etapas de preparo de amostra poderão ser mais simplificadas, facilitando o emprego da técnica em análise de rotina.

A técnica de ETAW-AAS completará 30 anos de existência em 2002. Entretanto, durante os primeiros 15 anos, seu desenvolvimento e aplicação foram bastante restritos. Depois disso, a introdução de algumas modificações permitiu avanços no seu desenvolvimento e diversos trabalhos foram e estão sendo realizados, mostrando a potencialidade e a versatilidade desta técnica

O crescente interesse na utilização da técnica de ETAW-AAS para a determinação de elementos ao nível de traços originou a presente revisão da literatura, na qual diferentes trabalhos são avaliados através das principais figuras de mérito (exatidão, precisão, limite de detecção e massa característica).

Além disso, o amadurecimento atingido por esta técnica está levando alguns pesquisadores a aprofundar os estudos relativos aos processos de atomização e de interferências, os quais são pouco conhecidos. Por outro lado, a idéia inicial de adaptar o filamento de tungstênio aos equipamentos comerciais e disponíveis de absorção atômica também evoluiu e, atualmente, existem grupos preocupados em desenvolver equipamentos dedicados para operação com os fornos de filamento de tungstênio.

A avaliação destes aspectos, à luz dos trabalhos já desenvolvidos, permite uma re-visão desta técnica mostrando que a comunidade científica está sempre buscando alternativas que viabilizem a solução de seus problemas.

\section{ATOMIZAÇÃO ELETROTÉRMICA COM FILAMENTO DE TUNGSTÊNIO}

O emprego de filamentos como alternativa para a ETAAS teve início na década de 70, apresentando imediatamente uma limitação: a inexistência de espectrômetros de absorção atômica com eletrônica adequada.

Em atomização eletrotérmica, a eficiência de formação da nuvem atômica está associada à taxa de aquecimento do atomizador, sendo esta diretamente proporcional à potência da fonte de aquecimento e inversamente proporcional à massa do atomizador e ao calor específico do material ${ }^{8}$. A taxa de aquecimento máxima no forno de grafite convencional é de $2 \mathrm{~K} \mathrm{~ms}^{-1}$, podendo atingir valores como $30 \mathrm{~K} \mathrm{~ms}^{-1}$ no filamento de tungstênio ${ }^{10}$. Esta alta taxa de aquecimento apresenta vantagens, permitindo a separação dos sinais de absorção atômica e não atômica. Com isso, o problema de isotermicidade é minimizado uma vez que a espécie de interesse e os concomitantes da matriz são atomizados e vaporizados em tempos diferentes, permitindo a obtenção separada dos sinais, principalmente para os elementos mais voláteis. Berndt and Schaldach ${ }^{5}$ observaram este fenômeno durante a determinação de cádmio e níquel em amostras de urina. O sinal do cádmio (mais volátil) aparece antes do sinal de absorção não atômica, enquanto o sinal do níquel aparece posteriormente.
Por outro lado, quando atomizadores com filamento de tungstênio são usados, o espectrômetro precisa de um detector eletrônico rápido para a leitura dos sinais transientes. Na ausência desta condição observa-se discrepância entre os resultados obtidos por diferentes pesquisadores, levando a conclusões nem sempre adequadas para justificar o mau funcionamento dos filamentos. A medida de sinais de curta duração, entretanto, somente se tornou menos crítica nos equipamentos produzidos a partir da década de 80 , com constantes de tempo inferiores a $50 \mathrm{~ms}{ }^{10}$.

Apesar desta limitação imposta pelos equipamentos no início dos estudos da ETAAS com filamentos, alguns trabalhos foram realizados na década 70, nos quais não somente diferentes características físicas dos sistemas, mas também a composição dos filamentos foi avaliada. Assim, foram feitos estudos utilizando filamentos de platina, tântalo, tungstênio e uma liga metálica composta por uma mistura de tungstênio $97 \% \mathrm{~m} / \mathrm{m}$ e rênio $3 \% \mathrm{~m} / \mathrm{m}^{10}$.

Os filamentos de platina foram pouco utilizados e não foi encontrado nenhum trabalho recente que os empregassem como atomizador. Isto se deve ao baixo ponto de fusão desse metal $\left(1768{ }^{\circ} \mathrm{C}\right)$, restringindo seu uso para a atomização de elementos mais voláteis, além de não permitir a etapa de limpeza da superfície por meio de aquecimento, que é realizado em temperaturas acima das empregadas na atomização ${ }^{11-14}$.

No entanto, os filamentos menos utilizados foram os construídos com tântalo, tendo sido encontrados somente dois trabalhos na literatura $^{15,16}$. Apesar do seu funcionamento não ser adequado para a determinação de elementos refratários e, além disso, formar compostos intermetálicos, a maior dificuldade encontrada para o seu emprego deve-se à sua baixa vida útil (o tântalo torna-se quebradiço após sucessivos ciclos de aquecimento e resfriamento) e também por se tratar de um filamento não industrializado.

Os filamentos de liga metálica de tungstênio e rênio também foram pouco utilizados. Os autores que os utilizaram argumentaram que esta liga, apesar de ter um ponto de fusão menor $\left(3300^{\circ} \mathrm{C}\right)$, era mais dúctil e mais resistente à oxidação do que os filamentos de tungstênio puro. Este tipo de filamento também não é comercializado e sua construção é feita em laboratório ${ }^{17,18}$.

Dentre todos os metais empregados na fabricação de filamentos e que foram utilizados para estudos em ETAAS, o tungstênio é aquele que apresenta o maior ponto de fusão $\left(3407^{\circ} \mathrm{C}\right)$ e a menor pressão de vapor. Além disso, esse metal se caracteriza por uma elevada resistência química, sendo atacado significativamente apenas pela mistura de ácidos fluorídrico e nítrico ou através de fusão alcalina oxidante ${ }^{10}$. A popularização do tungstênio ocorreu principalmente devido ao mesmo possuir boas propriedades físico-químicas, mas, além disso, também contribui o fato de tratar-se de um componente fabricado industrialmente, o que lhe assegura uma boa precisão na fabricação, além do baixo custo e da facilidade de aquisição. Cabe ressaltar, ainda, o empenho e a persistência dos grupos de pesquisa que acreditaram na potencialidade deste material para o processo de atomização.

Os primeiros trabalhos que empregaram ETAW para AAS foram feitos no início da década de 70, desenvolvidos por Piepmeier e colaboradores ${ }^{6,19}$. Entretanto, estes e outros trabalhos ${ }^{20,21}$ realizados até a metade dos anos 80, não apresentaram subsídios convincentes, como a análise de amostras reais, que pudessem despertar um maior interesse na comunidade científica.

Isto só aconteceu após a publicação feita por Berndt e Schaldach ${ }^{5}$, em 1988, onde apresentaram um sistema aberto para operação com filamento de tungstênio. Os resultados obtidos a partir de soluções de referência mostraram a potencialidade desse atomizador para a determinação de $\mathrm{Ba}, \mathrm{Cd}, \mathrm{Co}, \mathrm{Cr}, \mathrm{Eu}, \mathrm{Mn}, \mathrm{Ni}, \mathrm{Pb}, \mathrm{Sn}$ e V, quando foi utilizada uma mistura de $90 \%$ de argônio e $10 \%$ de $\mathrm{H}_{2}$ como gás de 
purga. A presença do hidrogênio nos processos de evaporação e de atomização em superfícies metálicas apresenta um aumento na sensibilidade da análise o qual, em alguns casos, é proporcional à concentração de hidrogênio e oxigênio. Por outro lado, algumas espécies não podem ser determinadas na ausência de hidrogênio, mostrando a sua importância nos processos de formação dos átomos da espécie de interesse. A composição do gás proposta $(90 \% \mathrm{Ar}+10 \%$ $\mathrm{H}_{2}$ ) permite um ambiente redutor que evita a formação de óxidos de tungstênio, os quais podem recombinar-se com a espécie de interesse na fase gasosa, diminuindo a sensibilidade, uma vez que interfere nos mecanismos de atomização. Além disso, a presença de hidrogênio evita o desgaste do filamento devido à reação com o oxigênio, durante a atomização, aumentando o tempo de vida útil do mesmo. Quando o método foi aplicado a amostras certificadas de urina sintética, as concentrações encontradas para $\mathrm{Cd}, \mathrm{Cr}, \mathrm{Ni}$ e $\mathrm{Pb}$, foram concordantes com os valores certificados. Estes resultados mostraram que este tipo de sistema poderia ser empregado para a determinação de outros elementos, assim como em outros tipos de amostras.

Desde então, o filamento de tungstênio em ETAAS vem sendo empregado por diversos grupos de pesquisa, especialmente no Brasil, Chile e Estados Unidos, que desenvolvem e aplicam a técnica de ETAW. A principal diferença entre os grupos é que os trabalhos desenvolvidos no Brasil e no Chile utilizam equipamentos comerciais de absorção atômica, aos quais o filamento de tungstênio é adaptado. Por outro lado, nos trabalhos realizados nos Estados Unidos, foram propostos equipamentos dedicados para a operação com filamento de tungstênio. É importante ressaltar essa diferença, uma vez que a alta taxa de aquecimento do filamento observada nos equipamentos adaptados compromete a detecção e pode afetar a sensibilidade da medida analítica.

A sensibilidade alcançada numa análise por espectrometria atômica está diretamente relacionada com a eficiência da formação de átomos da espécie de interesse. Os primeiros estudos sobre mecanismos de atomização em superfície de tungstênio foram realizados por Sychra et al. ${ }^{22}$ Em 1987, Muzgin et al. ${ }^{23}$ descreveram um modelo teórico para a formação da nuvem atômica e propuseram mecanismos de atomização para diferentes grupos de elementos. Na verdade, dependendo das condições empregadas na análise, poucos processos para a formação de átomos livres podem ser associados à ETAW. Assim, se a atomização ocorre numa atmosfera de argônio, o processo envolve predominantemente a dissociação térmica de óxidos:

$\mathrm{MO}_{(\mathrm{s})} \rightleftarrows \mathrm{M}_{(\mathrm{g})}+1 / 2 \mathrm{O}_{2(\mathrm{~g})}$

Se a ETAW é modificada com carbono, os limites de detecção para $\mathrm{Co}, \mathrm{Fe}, \mathrm{Mn}$, Ni e, especialmente, $\mathrm{Al}, \mathrm{Be}, \mathrm{Sr}, \mathrm{Si}$ são menores devido à reação:

$\mathrm{MO}(\mathrm{s})+\mathrm{C}_{(\mathrm{g})} \rightleftarrows \mathrm{M}_{(\mathrm{g})}+\mathrm{CO}_{(\mathrm{g})}$

Por outro lado, para os elementos como Cr, Ti, V e terras raras, os limites de detecção são maiores devido à formação dos respectivos carbetos, cuja dissociação é mais difícil de ocorrer:

$\mathrm{MO}_{(\mathrm{s})}+2 \mathrm{C}_{(\mathrm{s})} \rightleftarrows \mathrm{MC}_{(\mathrm{s})}+\mathrm{CO}_{(\mathrm{g})}$

$\mathrm{MC}_{(\mathrm{s})} \rightleftarrows \mathrm{M}_{(\mathrm{g})}+\mathrm{C}_{(\mathrm{g})}$

Esses mecanismos mostram a desvantagem da modificação da superfície do filamento de tungstênio com carbono e, além disso, os carbetos de tungstênio são quebradiços e possuem pontos de ebulição inferiores ao do metal puro. Com isso, a vida útil do filamento será reduzida.
Limites de detecção mais baixos podem ser encontrados para elementos que formam óxidos refratários e carbetos quando é utilizada uma mistura de argônio e hidrogênio, que protege o filamento, evitando a sua queima, uma vez que ocorre a reação de redução:

$\mathrm{MO}_{(\mathrm{s})}+\mathrm{H}_{2(\mathrm{~g})} \rightleftarrows \mathrm{M}_{(\mathrm{g})}+\mathrm{H}_{2} \mathrm{O}_{(\mathrm{g})}$

Apesar da eficiência de formação da nuvem atômica estar associada à taxa de aquecimento do atomizador, o processo de atomização pode ser mais bem caracterizado pela obtenção de um ambiente isotérmico do que propriamente pela temperatura final obtida no atomizador. Estudos sobre a distribuição da temperatura foram realizados por Chakrabarty et al. tanto na superfície ${ }^{24}$ como na fase gaso$\mathrm{sa}^{25}$ de um atomizador de tungstênio. Entretanto, como este estudo foi realizado para tubos de tungstênio, o comportamento do sistema pode não ser o mesmo daquele observado para os filamentos de tungstênio.

Recentemente Santos et al. ${ }^{26}$ realizaram estudos termogravimétricos a fim de investigar os mecanismos de decomposição para compostos de $\mathrm{Pb}$ em superfície de tungstênio. Os estudos foram feitos em uma superfície de tungstênio, sob a mesma atmosfera que usualmente é utilizada para os trabalhos com filamentos para atomização eletrotérmica, isto é, a mistura de Ar com $10 \%$ de $\mathrm{H}_{2}$. Neste trabalho os autores simulam as etapas de secagem e pirólise por termogravimetria de alguns sais de $\mathrm{Pb}$ na presença e na ausência de alguns modificadores químicos, tais como glicose e os ácidos ascórbico, oxálico e tartárico, bem como alguns possíveis interferentes, como o $\mathrm{NaNO}_{3}$. Os compostos intermediários e resíduos da etapa de pirólise foram caracterizados por difração de raios-X. Os mecanismos apresentados fornecem dados para melhor compreender os parâmetros envolvidos em ETAW-AAS, os quais podem ajudar a propor condições para contornar ou eliminar as possíveis interferências. No entanto, os mecanismos para decomposição das espécies de $\mathrm{Pb}$, em geral, passam pela formação do $\mathrm{PbO}$ por aquecimento, que posteriormente é reduzido por $\mathrm{H}_{2}$ para atomização do mesmo.

A medida dos sinais de absorbância obtidos em ETAW-AAS geralmente é feita pela altura do sinal, em função da alta taxa de aquecimento do filamento, o que resulta em uma melhor sensibilidade. Apesar da área do sinal fornecer melhor repetibilidade e estar menos susceptível a interferência, resulta em menor sensibilidade para este tipo de atomizador, pois os rápidos sinais gerados quando são integrados fornecem pequenas variações de áreas, para diferentes concentrações.

Com base nos resultados experimentais apresentados na literatura, obtidos para as medidas de temperatura em função da voltagem aplicada, é possível desenvolver as seguintes equações empíricas que podem ser empregadas para estimar as temperaturas do filamento e da fase gasosa (3 mm de distância do filamento):

$\mathrm{T}_{\text {(filamento) }}=2417-2402 \mathrm{e}^{-[\mathrm{V} / 3,16]}$
$\mathrm{T}_{\text {(fase gasosa) }}=1,7+173 \mathrm{~V}+17,7 \mathrm{~V}^{2}-3 \mathrm{~V}^{3}+0,1 \mathrm{~V}^{4}$

onde $\mathrm{V}$ é a voltagem aplicada em volts e $\mathrm{T}$ é a temperatura em ${ }^{\circ} \mathrm{C}$.

Deve-se ressaltar, no entanto, que essas equações somente são válidas para os filamentos de tungstênio de $10 \mathrm{~A}(15 \mathrm{~V}, 150 \mathrm{~W}) \mathrm{e}$ para vazão do gás em torno de $1 \mathrm{~L} \mathrm{~min}^{-1}$. Diferentes configurações e condições de otimização dos sistemas podem resultar em diferentes temperaturas.

Dessa maneira, quando uma voltagem de $9,50 \mathrm{~V}$ é aplicada, as temperaturas obtidas no filamento e na fase gasosa são de $2298^{\circ} \mathrm{C}$ e $1485^{\circ} \mathrm{C}$, respectivamente. Se a voltagem aplicada é de $3,40 \mathrm{~V}$, uma temperatura de $1598{ }^{\circ} \mathrm{C}$ é obtida no filamento e de $690^{\circ} \mathrm{C}$ na fase gasosa, estando estes valores próximos àqueles obtidos experimen- 
talmente por Bruhn et al. ${ }^{27}$, que também utilizou um filamento de $150 \mathrm{~W}$.

A temperatura da fase gasosa também pode ser determinada experimentalmente pelo método de duas linhas, a qual é descrita por Silva et al. ${ }^{28}$, onde $10 \mu \mathrm{L}$ de uma solução de Sn de concentração de $500 \mu \mathrm{g} \mathrm{L}^{-1}$ é depositada sobre o filamento e o sinal de absorbância é medido nos comprimentos de onda de $284,0 \mathrm{~nm}\left(\mathrm{~A}_{284}\right)$ e $286,3 \mathrm{~nm}$ $\left(\mathrm{A}_{286}\right)$. Uma vez medidas as intensidades dos sinais, a seguinte equação pode ser empregada para determinar a temperatura ( $T$, Kelvin) da fase gasosa:

$\mathrm{T}_{\text {(duas linhas) }}=2143 / \log \left(4,90 \mathrm{~A}_{286} / \mathrm{A}_{284}\right)$

Considerando o objetivo proposto para este trabalho, os diversos artigos sobre o assunto encontrados na literatura foram agrupados de acordo com as suas semelhanças químicas ou aplicações, a fim de melhorar a compreensão das figuras de mérito dos mesmos.

\section{DETERMINAÇÃO DE Pb EM SANGUE}

A intoxicação por $\mathrm{Pb}$ causa danos ao sistema nervoso central, cérebro, rins e sistema reprodutor. Em muitos países, é a principal causa do envenenamento em crianças, principalmente em populações que residem em áreas de riscos, como as regiões metropolitanas. A concentração do $\mathrm{Pb}$ no sangue é utilizada como indicador na avaliação da exposição a este elemento tóxico e sua determinação é de extrema importância.

Com este argumento, aliado à proposta de redução dos custos para as análises e à possibilidade de fabricação de um ETAW-AAS portátil, direcionado para a determinação de $\mathrm{Pb}$ em amostras de sangue, os trabalhos realizados por Parsons et al. ${ }^{29}$, Krug et al. ${ }^{8}$ e Salido et al. ${ }^{30}$ geraram os resultados apresentados na Tabela 1.

É possível observar que a técnica de ETAW-AAS mostrou-se bastante adequada para a determinação de baixas concentrações de $\mathrm{Pb}$, em amostras de sangue, apresentando limites de detecção em torno de $2 \mu \mathrm{g} \mathrm{dL}^{-1}$. Apesar dos diferentes métodos utilizados, tem-se massas características próximas, desvios relativos razoáveis e boa concordância entre os resultados obtidos e os esperados.

O método empregado por Parsons et al. ${ }^{29}$ parece ser o mais adequado para trabalhos de rotina em laboratório de análises clínicas. O preparo da amostra é rápido e feito por diluição (10x) com $0,2 \% \mathrm{~m} / \mathrm{v}$ de $\mathrm{NH}_{4} \mathrm{H}_{2} \mathrm{PO}_{4}, 0,5 \%$ v/v de Triton X-100 e 0,2\% v/v de $\mathrm{HNO}_{3}$. A calibração do equipamento foi realizada com o emprego de solução analítica contendo todos os reagentes usados na diluição.

Krug et $a l .{ }^{8}$ também empregaram esse método de diluição com reagentes, no entanto, a calibração do equipamento foi feita com o auxílio de solução analítica contendo a matriz, ou seja, fizeram uso de uma amostra certificada, com baixa concentração de $\mathrm{Pb}$, que foi adicionada junto aos padrões. Este método, apesar de reproduzir a matriz e eliminar a interferência causada pelo efeito da mesma, pode dificultar o seu emprego em análises de rotina, em função do custo envolvido.

Salido et al. ${ }^{30}$ propuseram a extração líquido-líquido para contornar o problema do efeito de matriz. A extração foi feita utilizando o agente quelante pirrolidinaditiocarbamato de amônio (APDC) e metil isobutil cetona.

Recentemente, Zhou et al. ${ }^{31}$ também realizaram estudos para o $\mathrm{Pb}$ em amostras de sangue, com o propósito de avaliar os diferentes tipos de filamentos comerciais disponíveis, que podem ser empregados como atomizador. O método empregado no preparo da amostra e calibração foi semelhante ao empregado por Krug et al. ${ }^{8}$ e, nesse trabalho, os autores ressaltam que os melhores resultados foram encontrados quando era empregado um filamento maior, o qual propiciou a obtenção de um melhor limite de detecção. A metodologia foi avaliada com o emprego de materiais de referência, obtendo-se bons resultados.

De um modo geral, independente do método empregado no preparo da amostra e calibração do equipamento, os resultados são animadores e seria interessante a fabricação, em escala industrial, de um equipamento portátil de ETAW-AAS direcionado para a determinação de $\mathrm{Pb}$ em amostras de sangue, o qual poderia ser utilizado em laboratórios de análises clínicas e hospitais, conforme evidenciaram os resultados obtidos ${ }^{29,30}$.

\section{ANÁLISE DE ÁGUA E SOLUÇÃo DE HEMODIÁLISE}

Muitas técnicas são descritas na literatura para determinação de elementos traço em amostras de água, mas algumas delas são um tanto demoradas e/ou caras.

Silva et al. ${ }^{28}$ analisaram águas de rio usando um filamento de tungstênio num sistema fechado, o qual mostrou ser uma alternativa simples e adequada para determinar bário, em baixas concentrações. Bruhn et al. ${ }^{27,32}$ otimizaram as condições para a utilização de um filamento num sistema aberto para determinar vários elementos em águas por ETAW-AAS. A Tabela 2 mostra as principais figuras de mérito encontradas por estes grupos de pesquisa e inclui também os resultados obtidos no trabalho desenvolvido por Luccas et al. ${ }^{33}$, os quais determinaram $\mathrm{Al}$ em solução de hemodiálise. Apesar de serem matrizes diferentes, os resultados estão mostrados de forma conjunta, uma vez que os sistemas empregados são semelhantes.

Os resultados obtidos por Silva et al. ${ }^{28}$ e Bruhn et al. ${ }^{27}$ apresentam boa concordância com os valores de referência, bons limites de detecção e baixos RSD's, mostrando que os métodos desenvolvidos por estes autores, para a determinação desses elementos em baixas

Tabela 1. Figuras de mérito obtidas na determinação de $\mathrm{Pb}$ em amostras de sangue

\begin{tabular}{|c|c|c|c|c|c|}
\hline \multirow[t]{2}{*}{ Grupos } & \multirow[t]{2}{*}{$\mathrm{m}_{\mathrm{o}}(\mathrm{pg})$} & \multirow[t]{2}{*}{$\mathrm{LD}\left(\mu \mathrm{g} \mathrm{dL^{-1 }}\right)$} & \multirow[t]{2}{*}{$\operatorname{RSD}(\%)$} & \multicolumn{2}{|c|}{ Resultado das análises* } \\
\hline & & & & $\mathrm{V}_{\mathrm{M}}\left(\mu \mathrm{g} \mathrm{dL}^{-1}\right)$ & $\mathrm{V}_{\mathrm{R}}\left(\mu \mathrm{g} \mathrm{dL}^{-1}\right)$ \\
\hline Parsons et al. ${ }^{29}$ & 26 & 2 & $4,4-13,7$ & $\begin{array}{c}4,2 \pm 0,2 \\
50,5 \pm 2,2\end{array}$ & $\begin{array}{l}5,01 \pm 0,09 \\
48,3 \pm 2,2\end{array}$ \\
\hline Krug et $a l .{ }^{8}$ & 15 & 1,9 & $6,7-16,9$ & $\begin{array}{c}8,3 \pm 1,4 \\
40,3 \pm 3,2\end{array}$ & $\begin{array}{r}6,7 \pm 1,2 \\
39,8 \pm 2,2\end{array}$ \\
\hline Salido et al. ${ }^{30}$ & 28 & 2,4 & $1,1-8,2$ & $\begin{array}{r}4,67 \pm 0,38 \\
38,53 \pm 1,81\end{array}$ & $\begin{array}{r}4,04 \pm 0,15 \\
39,36 \pm 0,36\end{array}$ \\
\hline
\end{tabular}

$\mathrm{m}_{0}=$ massa característica; $\mathrm{LD}=$ limite de detecção; $\mathrm{RSD}=$ desvio padrão relativo; $*$ material certificado; $\mathrm{V}_{\mathrm{M}}=$ valor medido; $\mathrm{V}_{\mathrm{R}}=$ valor de referência 
Tabela 2. Figuras de mérito obtidas na determinação de diferentes elementos traço em amostras de água e solução de hemodiálise

\begin{tabular}{|c|c|c|c|c|c|c|}
\hline \multirow[t]{2}{*}{ Grupos } & \multirow[t]{2}{*}{ Analito } & \multirow[t]{2}{*}{$\mathrm{m}_{\mathrm{o}}(\mathrm{pg})$} & \multirow[t]{2}{*}{$\mathrm{LD}\left(\mu \mathrm{g} \mathrm{L}^{-1}\right)$} & \multirow[t]{2}{*}{$\operatorname{RSD}(\%)$} & \multicolumn{2}{|c|}{ Resultado das análises* } \\
\hline & & & & & $\mathrm{V}_{\mathrm{M}}\left(\mu \mathrm{g} \mathrm{L}^{-1}\right)$ & $\mathrm{V}_{\mathrm{R}}\left(\mu \mathrm{g} \mathrm{L}^{-1}\right)$ \\
\hline \multirow[t]{2}{*}{ Silva et $a l .{ }^{28}$} & $\mathrm{Ba}$ & 3,6 & $2 \mathrm{pg}$ & $0,6-2,2$ & $10,0 \pm 0,1$ & $10,7 \pm 0,1$ \\
\hline & & & & & $116,6 \pm 1,4$ & $113,0 \pm 0,4$ \\
\hline \multirow[t]{6}{*}{ Bruhn et al. ${ }^{27}$} & $\mathrm{Cd}$ & 0,3 & 0,06 & $4,3-5,9$ & $11,4 \pm 0,75$ & $12,2 \pm 1,0$ \\
\hline & Co & 7 & 1,2 & $3,4-4,5$ & $25,5 \pm 2,01$ & $23,5 \pm 0,8$ \\
\hline & $\mathrm{Cr}$ & 5 & 0,3 & $1,8-3,6$ & $20,3 \pm 2,57$ & $19,0 \pm 0,6$ \\
\hline & $\mathrm{Mn}$ & 3 & 0,4 & $4,9-6,8$ & $37,2 \pm 5,07$ & $35,1 \pm 2,2$ \\
\hline & $\mathrm{Ni}$ & 8 & 1,2 & $3,1-6,4$ & $62,5 \pm 0,88$ & $60,6 \pm 7,3$ \\
\hline & $\mathrm{Pb}$ & 14 & 2,3 & $3,4-3,4$ & $35,8 \pm 1,51$ & $35,3 \pm 0,9$ \\
\hline \multirow[t]{2}{*}{ Luccas et al. ${ }^{33}$} & $\mathrm{Al}$ & 39 & 2 & $6,9-30,4$ & $7,2 \pm 0,5$ & $7,2 \pm 0,1$ \\
\hline & & & & & $12,5 \pm 3,8$ & $12,4 \pm 0,5$ \\
\hline
\end{tabular}

$\mathrm{m}_{0}=$ massa característica $\mathrm{LD}=$ limite de detecção; $\mathrm{RSD}=$ desvio padrão relativo; $*$ amostra ou material certificado; $\mathrm{V}_{\mathrm{M}}=$ valor medido; $\mathrm{V}_{\mathrm{R}}=$ valor de referência (informado no certificado ou obtido por outra técnica)

concentrações, em diferentes tipos de amostras de água, são adequados e com boa reprodutibilidade.

A determinação de $\mathrm{Al}$ em solução de hemodiálise mostrou boa concordância entre os valores obtidos e os esperados, mas, por outro lado, altos RSD's foram encontrados. A sensibilidade encontrada para a determinação de Al por ETAW-AAS foi baixa, como se observa pela elevada massa característica e, além disso, os valores de concentrações normais do elemento em solução de hemodiálise encontram-se próximos do LD, em torno de 3 a 4 vezes maior, estando dessa maneira mais suscetíveis a flutuações no sinal medido pelo equipamento. Por outro lado, considerando-se que um número maior de medidas pode ser realizado, visando aumentar a confiabilidade dos resultados nas concentrações normais, este problema poderia ser superado. Considerando este aspecto, a construção direcionada de um equipamento de baixo custo e fácil manipulação seria interessante aos centros clínicos que realizam hemodiálise.

Ostrega et al..$^{34}$ determinaram $\mathrm{Cd} \mathrm{e} \mathrm{Pb}$, simultaneamente, em águas naturais. Os RSD's encontrados foram inferiores a $8 \%$, a $\mathrm{m}_{0}$ foi de 0,8 e 1,8 pg para o $\mathrm{Cd}$ e $\mathrm{Pb}$, respectivamente. Knochen et al. ${ }^{35}$ realizaram estudos para a determinação de $\mathrm{Cr}$ em amostras de águas de rio e soluções aquosas, obtendo limite de detecção de 8 pg e massa característica de $13 \mathrm{pg}$, com RSD de 3\%, para níveis de concentração de 0,4 ng.

A sensibilidade obtida aliada à simplicidade e ao tempo de vida do atomizador tornam essa técnica uma alternativa interessante para a análise de águas.

\section{EMPREGO DE SISTEMA DE FLUXO NA SEPARAÇÃO E PRÉ-CONCENTRAÇÃO}

A maior dificuldade na utilização de um filamento como atomizador, para ETAAS, deve-se ao fato de ser um sistema de atomização não isotérmico, ficando mais sujeito a interferências na fase de vapor, devido às recombinações entre a espécie de interesse e os concomitantes da matriz. Essas interferências são mais severas do que no sistema isotérmico, que é uma das características do forno de grafite, especialmente os instrumentos equipados com sistema de aquecimento transversal (THGA). Estudos de interferência realizados por Chauvin et $a l .{ }^{18}$ mostraram que a maioria das interferências era eliminada ou reduzida significativamente quando a medida do sinal era feita na forma de área do pico e não como altura do sinal. As interferências persistentes eram oriundas da fase de vapor e o único modo de eliminá-las era com o emprego de métodos adequados no preparo da amostra e/ou na separação da matriz, visando reduzir a quantidade dos concomitantes da mesma e, desta maneira, minimizar os problemas de interferência resultantes de recombinações na fase de vapor. Por outro lado, Bruhn et $a l .{ }^{36}$ realizaram um experimento visando determinar se as interferências obtidas na determinação de chumbo em cabelo e sangue ocorriam na fase gasosa ou na fase condensada. Para isso, foram introduzidas alíquotas de solução de chumbo e de possíveis interferentes, separadamente, nas extremidades opostas do filamento. Os resultados obtidos evidenciaram que as interferências ocorriam na fase condensada. A partir deste trabalho é possível supor que outras espécies também possam estar sujeitas à interferência na fase condensada, não sendo correta a generalização feita pela maioria dos autores de que as interferências ocorrem na fase gasosa.

Buscando esclarecer os processos de interferências em ETAWAAS, Oliveira et al. ${ }^{37}$ realizaram estudos da influência de $\mathrm{Na}, \mathrm{K}, \mathrm{Ca}$ e $\mathrm{Mg}$ na atomização do $\mathrm{Pb}$. Para tal foram simuladas várias condições, onde variaram a concentração dos possíveis interferentes, a composição do gás de purga e a altura de observação do filamento. Os resultados encontrados pelos autores nesses experimentos mostraram que os processos de interferência ocorrem preferencialmente na fase condensada, não sendo observada interferência na fase gasosa. Além disso, a atomização do $\mathrm{Pb}$ foi melhor, na ausência dos possíveis interferentes, quando foi utilizado como gás de purga a mistura $\mathrm{Ar}$ e $\mathrm{H}_{2}$ (9:1) durante as etapas de pirólise e atomização. Por outro lado, as interferências de $\mathrm{Na}$ e Ca foram desprezíveis quando a etapa de pirólise foi realizada somente com o Ar como gás de purga. Segundo os autores, os possíveis interferentes estudados podem estar diretamente envolvidos nas reações de competição pelo $\mathrm{H}_{2}$ nos processos em fase condensada.

Com o intuito de minimizar a interferência e aumentar o poder de detecção por ETAW-AAS, Barbosa et al. ${ }^{38}$ propuseram um sistema automatizado de separação e pré-concentração por eletrodeposição de $\mathrm{Pb}$ no filamento. A amostra é bombeada, à vazão de $1 \mathrm{~mL} \mathrm{~min}{ }^{-1}$, para o interior de um eletrodo de Pt (ânodo) e o $\mathrm{Pb}$ é depositado sobre o filamento (cátodo), por $120 \mathrm{~s}$, pela aplicação de um potencial de $9 \mathrm{~V}$, enquanto a maioria dos concomitantes da matriz são descartados. Posteriormente, o eletrodo é removido, um programa de temperatura e tempo é acionado e a medida é realizada. Com este sistema, o limite de detecção obtido foi de $0,2 \mu \mathrm{g} \mathrm{L}^{-1}$ para o $\mathrm{Pb}$, o RSD foi menor que $5 \%$ e o sistema apresentou um fator de enriquecimento igual a 25 . A presença de $\mathrm{NaCl}$ ou $\mathrm{KCl}$ em concentrações de até $2 \% \mathrm{~m} / \mathrm{v}$ e $\mathrm{CaCl}_{2}$ ou $\mathrm{MgCl}_{2}$ de até $5 \% \mathrm{~m} / \mathrm{v}$ não apresentou interferência e os resultados das análises das amostras certificadas foram satisfatórios. 
A literatura descreve diversos trabalhos que empregam a separação líquido-sólido para pré-concentrar a espécie de interesse.

Bruhn et al. ${ }^{32}$ descreveram o pré-tratamento de amostras de água, vinhos de mesa e refrigerantes, para a determinação de $\mathrm{Cd}, \mathrm{Co}, \mathrm{Cr}$, $\mathrm{Mn}, \mathrm{Ni}$ e $\mathrm{Pb}$, após a pré-concentração por evaporação ou por separação da matriz e pré-concentração com a resina comercial Chelex100 , obtendo bons resultados.

Silva et al. ${ }^{39}$ empregaram uma resina comercial (Chelex-100) para determinação de chumbo, num sistema em linha. Durante $60 \mathrm{~s}$, a amostra passa pela coluna que está adaptada a um amostrador automático e, em seguida, o chumbo é eluído com $20 \mu \mathrm{L}$ de $\mathrm{HCl} 2 \mathrm{~mol} \mathrm{~L}^{-1}$ e depositado sobre o filamento. A seguir é acionado o programa de temperatura e tempo e a medida analítica é realizada. Com este sistema foi possível obter um fator de enriquecimento igual a 64 e o processamento de até 30 amostras $\mathrm{h}^{-1}$. A presença de até $1000 \mathrm{mg} \mathrm{L}^{-1}$ de $\mathrm{Ca}, \mathrm{Mg}$, $\mathrm{Na}$ ou $\mathrm{K}$ não afetou os resultados, os quais foram comparados com aqueles obtidos com a técnica de ETAAS com forno de grafite de aquecimento transversal.

Silva et $a l .{ }^{40}$ empregaram este sistema também para a análise de $\mathrm{Cd}$, $\mathrm{Ni}$ e $\mathrm{Pb}$ usando o fulereno $\left(\mathrm{C}_{60}\right)$ como agente de separação e préconcentração. As principais figuras de mérito estão apresentados na Tabela 3. Os resultados mostram a potencialidade do sistema, alcançando excelentes valores para o limite de detecção e a reprodutibilidade. A exatidão do método desenvolvido foi validada através da análise de material certificado. Além disso, o sistema não é afetado pela presença de $\mathrm{Ca}, \mathrm{Mg}$, $\mathrm{Na}$ ou $\mathrm{K}$ em concentrações até $10^{6}$ vezes maiores que a concentração dos analitos investigados. $\mathrm{O}$ preço da coluna, segundo os autores, é de 15 dólares, o que não compromete o custo final das análises, já que é possível a reutilização de uma mesma coluna por vários ciclos de pré-concentração, sem perda da eficiência. A comparação com o trabalho anterior mostrou que o fulereno é um reagente de pré-concentração mais adequado do que a resina.

Com base nestes trabalhos, pode-se concluir sobre a capacidade desta técnica observando-se, de um modo geral, que os sistemas de separação e pré-concentração por ETAW-AAS, em linha, são capazes de fornecer resultados precisos e exatos, mesmo quando se trabalha com concentrações da ordem de $\mathrm{ng} \mathrm{L}^{-1}$, em matrizes complexas e pouco diluídas. Além disso, fornecem condições ideais para a determinação automatizada de espécies em concentrações baixas, podendo ser empregada em procedimentos de rotina normal nos laboratórios.

\section{MONITORAMENTO DE MARCADORES ALIMENTÍCIOS EM ANIMAIS}

A determinação do valor nutritivo de alimentos consumidos por animais é necessária e é realizada através de experimentos de digestibilidade envolvendo a coleta total, porém, esse tipo de estudo é bastante oneroso. Uma alternativa a esse procedimento é a utilização de marcadores externos, que permitem o estudo de uma série de parâmetros como taxa de passagem da digesta pelo trato gastrointestinal e a produção do trânsito fecal.

Complexos metálicos, como os de Co, Cr, Dy e Eu, são usados para determinar a taxa de passagem da fase líquida e sólida em digestas de ruminantes. A dificuldade da utilização desse procedimento reside na necessidade de se empregar grandes quantidades de marcadores, para a obtenção de valores satisfatórios, tendo em vista que esses elementos são normalmente determinados por espectrometria de absorção atômica com chama (FAAS), a qual apresenta baixa sensibilidade para lantanídeos. A utilização de ETAAS com forno de grafite não é uma alternativa adequada, uma vez que os lantanídeos possuem a propriedade de formar carbetos refratários no tubo de grafite, o que resulta numa baixa sensibilidade.

O monitoramento de marcadores foi feito por Lima et al. ${ }^{41}$, Lopes et al. ${ }^{42}$ e Silva et $a l .{ }^{43}$, os quais desenvolveram metodologias para a determinação de $\mathrm{Yb}$, Co e Eu/Dy, respectivamente, em amostras de digestas de animais (ovelhas) por ETAW-AAS. De acordo com os autores, é possível uma redução significativa nos custos, comparada aos métodos convencionais, uma vez que as massas de marcadores administradas aos animais são consideravelmente menores, compensando os custos elevados dos mesmos (e.g. US\$ 3500,00/ kg de $\mathrm{Yb}$ ). Os resultados da análise, em cada um dos trabalhos, foram concordantes com aqueles obtidos com outro método, como ETAAS com forno de grafite ou com o método catalítico-espectrofotométrico com injeção em fluxo.

Para o Yb, a massa característica $\left(\mathrm{m}_{0}\right)$ obtida foi de 7,1 pg, o LD foi $0,35 \mu \mathrm{g} \mathrm{g}^{-1}$, o RSD foi de $1,9 \%$ e os valores de concentração encontrados foram concordantes com o método comparativo. Também para o Co bons resultados foram obtidos: a $\mathrm{m}_{0}$ foi $23,1 \mathrm{pg}$; o LD foi $19,1 \mathrm{pg}$; o RSD foi de $0,5 \%$ e as concentrações também foram concordantes com o método comparativo. Silva et al. ${ }^{43}$ obtiveram resultados satisfatórios na determinação de Dy e Eu por filamento de tungstênio, com LD e LQ (limite de quantificação) semelhantes aos obtidos por ETAAS com forno de grafite. Nesse trabalho, a principal vantagem demonstrada pelo filamento de tungstênio em relação ao forno de grafite é o tempo de vida útil. Para ETAW-AAS o filamento resistiu a cerca de 200 ciclos de aquecimento enquanto o tubo de grafite suportou apenas 70 ciclos de aquecimento, tanto para Dy como para Eu. Além disso, as determinações em tubo de grafite foram dificultadas pela presença de efeitos de memória, o que não ocorreu para o filamento.

Como demonstrado por esses estudos, a técnica de absorção atômica com atomização eletrotérmica em filamento de tungstênio, apresentou resultados confiáveis, com adequada sensibilidade e

Tabela 3. Figuras de mérito obtidas na determinação de $\mathrm{Cd}$, Ni e $\mathrm{Pb}$ com separação e pré-concentração em linha com fulereno $\left(\mathrm{C}_{60}\right)$ em amostras de água ${ }^{40}$

\begin{tabular}{|c|c|c|c|c|c|c|}
\hline \multirow[t]{2}{*}{ Analito } & \multirow{2}{*}{$\mathrm{LD}\left(\mathrm{ng} \mathrm{L}^{-1}\right)$} & \multirow[t]{2}{*}{$\operatorname{RSD}(\%)$} & \multirow[t]{2}{*}{$\mathrm{FE}$} & \multirow{2}{*}{$\operatorname{ER~(\% )}$} & \multicolumn{2}{|c|}{ Resultado das análises } \\
\hline & & & & & $\mathrm{V}_{\mathrm{M}}\left(\mu \mathrm{g} \mathrm{L}^{-1}\right)$ & $\mathrm{V}_{\mathrm{R}}\left(\mu \mathrm{g} \mathrm{L}^{-1}\right)$ \\
\hline $\mathrm{Cd}$ & 2,2 & $<5$ & 97 & 47 & $\begin{array}{l}1,27 \pm 0,08 \\
24,7 \pm 1,0\end{array}$ & $\begin{array}{l}1,4 \pm 1,2 \\
20 \pm 1\end{array}$ \\
\hline $\mathrm{Ni}$ & 75 & $<6$ & 99 & 55 & $\begin{array}{r}2,4 \pm 0,1 \\
72,4 \pm 7,6\end{array}$ & $\begin{array}{r}3,3 \pm 1,6 \\
60 \pm 0,3\end{array}$ \\
\hline $\mathrm{Pb}$ & 23 & $<4$ & 149 & 82 & $\begin{array}{l}2,53 \pm 0,08 \\
37,7 \pm 1,9\end{array}$ & $\begin{array}{r}2,9 \pm 1,3 \\
40 \pm 2,2\end{array}$ \\
\hline
\end{tabular}

$\mathrm{LD}=$ limite de detecção; $\mathrm{RSD}=$ desvio padrão relativo; $\mathrm{FE}=$ fator de enriquecimento; $\mathrm{ER}=$ eficiência de retenção; $\mathrm{V}_{\mathrm{M}}=$ valor medido e $\mathrm{V}_{\mathrm{R}}$ = valor de referência 
reprodutibilidade. O pequeno consumo de amostra e a elevada sensibilidade reduzem o custo das determinações, tornando esta técnica especialmente atrativa em estudos de nutrição animal.

\section{EMPREGO DE MODIFICADORES QUÍMICOS}

A técnica de ETAAS está sujeita a interferências, tanto na fase condensada, quanto na fase de vapor. Para contornar este problema, Ediger $^{44}$, em 1975, propôs o uso de modificador da matriz. (modificador químico), com a finalidade de volatilizar o interferente ou, então, tornar o analito menos volátil, possibilitando a separação térmica mais eficiente dos concomitantes da matriz da amostra antes da etapa de atomização. Desde então, muitos trabalhos utilizando os mais diferentes tipos de modificadores químicos são encontrados na literatura. Em 1986, Schlemmer e Welz ${ }^{45}$ propuseram uma mistura de nitrato de paládio e nitrato de magnésio como um modificador químico adequado para mais de 20 elementos, resultando em temperaturas de pirólise entre 900 e $1400{ }^{\circ} \mathrm{C}$ e temperaturas de atomização em torno de $2000{ }^{\circ} \mathrm{C}$, para os elementos investigados.

Porém, existem poucos estudos a respeito do emprego de modificador químico para a técnica de ETAW-AAS e a maioria dos trabalhos foram realizados por um mesmo grupo de pesquisadores. No primeiro trabalho, Bruhn et al. ${ }^{36}$ estudaram o emprego de $\left(\mathrm{NH}_{4}\right)_{2} \mathrm{HPO}_{4}, \mathrm{NH}_{4} \mathrm{H}_{2} \mathrm{PO}_{4}$ e $\mathrm{Pd}\left(\mathrm{NO}_{3}\right)_{2}$ na determinação de $\mathrm{Pb}$ em amostras de sangue e cabelo. Segundo os autores, os melhores resultados foram obtidos com Pd. Em outro estudo ${ }^{46}$, determinaram $\mathrm{Cr}$ em materiais biológicos e os modificadores testados foram $\mathrm{Mg}\left(\mathrm{NO}_{3}\right)_{2}$, $\mathrm{Pd}\left(\mathrm{NO}_{3}\right)_{2}, \mathrm{NH}_{4} \mathrm{NO}_{3}$, ácido ascórbico e uma mistura desses modificadores. Os melhores resultados foram obtidos com a mistura de ácido ascórbico e $\mathrm{Mg}$. Posteriormente, utilizaram $\mathrm{Pd}\left(\mathrm{NO}_{3}\right)_{2}$, $\mathrm{Mg}\left(\mathrm{NO}_{3}\right)_{2}$, ácido ascórbico e uma mistura destes modificadores, na determinação de $\mathrm{Cd}$ e $\mathrm{Pb}$ em mexilhão ${ }^{47}$. Para os autores, todos os modificadores e suas misturas proporcionaram bons resultados, aumentando a sensibilidade e a estabilidade térmica, além de diminuir o sinal de fundo e aumentar a vida útil dos filamentos.

No entanto, esses trabalhos não apresentaram uma comparação dos resultados obtidos com e sem modificadores químicos nas análises das amostras, exceto as curvas de atomização e pirólise. Com isso, não dá para se ter uma idéia da vantagem real do emprego dos modificadores químicos em ETAW-AAS ou mesmo se seria possível fazer essas análises sem o uso do modificador. Na Tabela 4 estão apresentadas as figuras de mérito do único trabalho realizado por Bruhn et al. ${ }^{48}$ que traz esta comparação, feita para a determinação de $\mathrm{Cd}$ em amostras de cabelo e sangue, com os modificadores químicos
$\left(\mathrm{NH}_{4}\right)_{2} \mathrm{HPO}_{4}, \mathrm{NH}_{4} \mathrm{H}_{2} \mathrm{PO}_{4}$ e $\mathrm{Pd}\left(\mathrm{NO}_{3}\right)_{2}$. Conforme descrito anteriormente, os autores observaram que os melhores resultados foram obtidos com Pd.

Como se observa, os resultados da Tabela 4 mostram que o ganho proporcionado com o uso de modificador químico não foi significativo, uma vez que as massas características foram semelhantes, os limites de detecção próximos e o RSD foi melhor quando não foi utilizado modificador. A exatidão na determinação da concentração de cádmio foi maior quando foi utilizado o Pd como modificador químico, no entanto, os resultados foram concordantes em todas as condições de análise empregadas.

A conclusão a que se pode chegar, com base nos estudos feitos por Bruhn et al. ${ }^{48}$, é que o ganho proporcionado pelo uso de modificadores químicos não é significativo, uma vez que as análises são realizadas com a amostra em solução, após ser decomposta totalmente por digestão ácida, resultando em uma solução de matriz menos complexa e mais diluída. Além disso, o estudo foi realizado para a determinação de cádmio, o qual é menos sujeito ao efeito de interferência do que outras espécies químicas. Talvez, o emprego de modificadores químicos apresente resultados mais significativos na presença de outras espécies. Vale ressaltar ainda que o tungstênio, material que constitui o filamento, não é muito suscetível à interferência como outras espécies. Devido a suas propriedades ele é empregado como modificador químico em ETAAS com tubos de grafite a fim de minimizar efeitos de memória e formação de carbetos refratários. Desta forma, muitas das interferências observadas no forno de grafite podem não ser evidenciadas quando o filamento é utilizado e, talvez por isso, a maioria dos trabalhos com ETAW-AAS não empreguem modificadores químicos.

Em 2001, Hou et al. ${ }^{49}$ realizaram estudos do emprego de modificador químico permanente para determinações de $\mathrm{Cd}$, onde $200 \mu \mathrm{g}$ de irídio foram depositados sob a superfície do filamento. O uso deste modificador propiciou um aumento da vida útil do filamento, chegando a atingir 1000 ciclos de aquecimento, quando na maior parte dos trabalhos desenvolvidos normalmente são reportados de 150 a 300 ciclos de aquecimentos. No entanto, como já foi ressaltado, o Cd é um elemento volátil e os ciclos de aquecimentos para este elemento geralmente ocorrem em temperaturas mais baixas do que para os elementos não voláteis resultando, na maioria dos casos, numa vida útil maior dos atomizadores. Além disso, a complexidade da matriz também afeta a vida útil dos atomizadores. Outro fato que deve ser considerado é a relação custo/ beneficio, uma vez que os filamentos podem ser adquiridos a aproximadamente US\$ 0,50 e os modificadores químicos podem encarecer as análises.

Tabela 4. Figuras de mérito obtidas na determinação de Cd em amostras de cabelo e sangue com e sem o emprego de diferentes modificadores químico ${ }^{48}$

\begin{tabular}{|c|c|c|c|c|}
\hline Modificador & $\mathrm{m}_{0}(\mathrm{pg})$ & $\mathrm{LD}\left(\mu \mathrm{g} \mathrm{L}^{-1}\right)$ & $\begin{array}{c}\operatorname{RSD}(\%) \\
\mathrm{V}_{\mathrm{M}}\left(\mu \mathrm{g} \mathrm{g}^{-1}\right)\end{array}$ & Resultado das análises* \\
\hline Sem Modificador & 0,5 & 0,1 & 3,6 & $\begin{array}{c}0,106 \pm 0,015^{\mathrm{a}} \\
5,60 \pm 1,24^{\mathrm{b}}\end{array}$ \\
\hline$\left(\mathrm{NH}_{4}\right)_{2} \mathrm{HPO}_{4} 0,33 \mathrm{mg} \mathrm{mL}^{-1}$ & 0,5 & 0,09 & 4,0 & $\begin{aligned} 0,103 & \pm 0,021^{\mathrm{a}} \\
5,47 & \pm 0,24^{\mathrm{b}}\end{aligned}$ \\
\hline $\mathrm{NH}_{4} \mathrm{H}_{2} \mathrm{PO}_{4} 0,29 \mathrm{mg} \mathrm{mL}^{-1}$ & 0,8 & 0,1 & 5,7 & $\begin{array}{c}0,096 \pm 0,003^{\mathrm{a}} \\
5,63 \pm 0,80^{\mathrm{b}}\end{array}$ \\
\hline $\mathrm{Pd}\left(\mathrm{NO}_{3}\right)_{2} 15 \mu \mathrm{g} \mathrm{mL}$ & 0,3 & 0,05 & 5,5 & $\begin{aligned} 0,093 & \pm 0,008^{\mathrm{a}} \\
5,43 & \pm 0,51^{\mathrm{b}}\end{aligned}$ \\
\hline
\end{tabular}

$\mathrm{m}_{0}=$ massa característica; $\mathrm{LD}=$ limite de detecção; $\mathrm{RSD}=$ desvio padrão relativo; $*$ amostras certificadas; $\mathrm{V}_{\mathrm{M}}=$ valor medido; $\mathrm{V}_{\mathrm{R}}=$ valor de referência 
Assim, talvez seja mais vantajoso o consumo de 3 filamentos ao invés de 1 , com o emprego do modificador permanente, para a determinação de $\mathrm{Cd}$, uma vez que este não é um elemento tão afetado pelos concomitantes da matriz. Desta forma, dependendo do tipo e do número de amostras e da freqüência analítica necessária, o analista pode optar por uma das duas possibilidades discutidas.

Considerando os estudos de modificadores químicos já realizados para os diversos metais, em vários tipos de matrizes, é possível concluir que os conhecimentos obtidos em ETAAS com tubos de grafite podem ser aplicados em ETAW-AAS, no que se refere à modificação de matriz e estabilidade térmica dos analitos. Talvez este seja o motivo de estudos deste tipo não despertar muito interesse entre os pesquisadores que trabalham com esta técnica. Entretanto, é importante que seja feita uma avaliação preliminar e uma adaptação das condições, uma vez que as condições dos ambientes de reação são diferentes.

\section{RECENTES AVANÇOS NA TÉCNICA DE ETAW-AAS}

A técnica de ETAAS geralmente é monoelementar, devido a dois fatores principais: o primeiro está relacionado ao comportamento termoquímico dos elementos e seus compostos; o outro, ainda mais limitante, deve-se ao custo do equipamento que, devido ao arranjo ótico necessário para determinações multielementares, pode ser comparado àquele de um espectrômetro de emissão óptica com fonte de plasma indutivamente acoplado (ICP OES).

$\mathrm{Na}$ tentativa de contornar parcialmente esses problemas, foi desenvolvido um equipamento multielementar de ETAW-AAS ${ }^{50,51}$. O arranjo do equipamento é interessante, no qual um único feixe de radiação, proveniente de até quatro fontes de radiação, passa no filamento para a leitura simultânea, e as radiações são somadas no feixe único com o auxílio de três grades (coarse grating, $60^{\circ}$ beam combiners). A correção do sinal de fundo é feita com a leitura de uma segunda linha, próxima daquela onde está sendo medido o sinal do analito. Wagner et al. ${ }^{50}$ determinaram $\mathrm{Cd}, \mathrm{Pb}$ e Cu em amostras de tecido de ostra e sedimento. Os resultados foram concordantes com os valores certificados, no entanto, a sensibilidade obtida foi baixa. Os limites de detecção encontrados para $\mathrm{Cu}, \mathrm{Cd}$ e $\mathrm{Pb}$ foram 20, 2 e $120 \mathrm{pg}$, respectivamente. Em outro trabalho realizado pelo mesmo grupo $^{51}$, utilizando o mesmo equipamento, foi feita a determinação desses analitos em amostras de água, obtendo-se resultados concordantes com o esperado, bem como melhor sensibilidade, obtida principalmente para o $\mathrm{Pb}$. Os limites de detecção encontrados foram 16 , 4 e 60 pg para $\mathrm{Cu}, \mathrm{Cd}$ e $\mathrm{Pb}$, respectivamente. A diferença entre esses valores leva à conclusão que o sistema não foi adequadamente otimizado no primeiro trabalho ou, mais provavelmente, como as amostras analisadas são diferentes, os limites de detecção refletem a maior complexidade da matriz no primeiro caso.

O grupo do professor Jones ${ }^{52,53}$ também desenvolveu um espectrômetro de ETAW portátil, onde o fornecimento de energia provém de uma bateria automotiva de $12 \mathrm{~V}$ e o sistema é controlado por um computador "laptop". As dimensões do equipamento são de aproximadamente $46 \mathrm{~cm}$ comprimento por $25 \mathrm{~cm}$ de largura e o custo total do investimento é de US\$ 6000. Com este equipamento, foi feita a determinação de $\mathrm{Cd}$ e $\mathrm{Pb}$, obtendo-se RSD's em torno de 5 a $10 \%$, LD's de $3 \mu \mathrm{g} \mathrm{Cd} \mathrm{L-1}$ (60 pg) e $1 \mu \mathrm{g} \mathrm{Pb} \mathrm{L}^{-1}(20 \mathrm{pg}$ ) e os resultados obtidos nas análises foram concordantes com os diferentes materiais certificados utilizados.

Neira et al..$^{54}$ desenvolveram uma interface e um programa computacional para operação sincronizada do amostrador automático e do atomizador eletrotérmico de filamento de tungstênio para o equipamento de absorção atômica.

Oliveira et al. ${ }^{9}$ avaliaram os programas de aquecimento empregados no filamento, em especial durante a etapa de secagem, utili- zando temperatura de secagem constante e variável, sendo esta a mais usual em todos os trabalhos. Para conseguir manter a temperatura constante, a tensão aplicada na etapa de secagem é reduzida gradativamente. Se este procedimento não for adotado, altas temperaturas podem ser alcançadas, tendo em vista que a tensão aplicada é convertida em calor no filamento, o qual é imediatamente consumido pela evaporação dos solventes, e à medida que o volume da solução da amostra vai sendo evaporado o calor no filamento também aumenta e a temperatura final da etapa de secagem pode chegar a $700{ }^{\circ} \mathrm{C}$, enquanto que no programa de tensão variável a temperatura máxima chega a $300{ }^{\circ} \mathrm{C}$. O resultado do emprego do programa de secagem com temperatura constante, segundo os autores, foi o aumento de sensibilidade para elementos mais voláteis, uma vez que minimizam as perdas dos mesmos na etapa de secagem, em especial para o $\mathrm{Cd}$. Para o $\mathrm{Pb}$ este aumento não foi tão evidenciado, já que este elemento apresenta um maior ponto de ebulição. Para o $\mathrm{Al}$ e o $\mathrm{Cr}$, que são menos voláteis, ambos os programas fornecem resultados semelhantes.

Ribeiro et al. ${ }^{55}$ estão realizando estudos para o desenvolvimento de um atomizador de quartzo com filamento de tungstênio (QTAW) para determinação de espécies gasosas, por AAS. O sistema proposto para a determinação de arsênio por geração de hidretos, em sistema de fluxo, apresentou resposta linear à calibração, além de dispensar a mistura de $\mathrm{Ar}$ e $\mathrm{H}_{2}$ (90:10\% v/v) como gás de purga, uma vez que o sistema produz $\mathrm{H}_{2}$ continuamente, mantendo assim o ambiente redutor dentro da cela e evitando a queima do filamento. Além disso, o filamento pode ser mantido sob tensão elevada entre as análises, proporcionando a obtenção de um ambiente mais isotérmico no interior da cela, além de poder selecionar a temperatura ideal para cada espécie de interesse.

Um trabalho recente na linha de desenvolvimento de novos equipamentos foi feito por Krivan et $a l .{ }^{56}$. Os autores desenvolveram, junto com uma empresa alemã (LaserSpec Analytik), um equipamento de AAS, no qual não é mais utilizada a lâmpada de cátodo oco (HCL - "hollow cathode lamp") ou EDL ("electrodeless discharge lamps"). O sistema de correção de fundo empregado atualmente é dispensado e, além disso, todo o sistema de monocromador e fotomultiplicadora pode ser substituído pelo emprego de um único componente eletrônico, o fotodiodo. Segundo os autores, o sistema é mais estável, simples de ser construído, com menor tamanho, mais barato, com correção automática do fundo e com elevada sensibilidade. Para demonstrar o desempenho do equipamento, foram feitos estudos para determinação de $\mathrm{Al}$ e $\mathrm{Cr}$ em amostras de água e sangue e foram analisadas amostras de grafite e dióxido de titânio na forma de suspensão.

As figuras de mérito obtidas neste trabalho, apresentadas na Tabela 5 , mostram que os resultados das análises foram concordantes com os valores esperados e bons LD's foram obtidos apesar dos altos RSD's, o que é justificável em função da complexidade das matrizes analisadas. Um dos aspectos observados pelos autores é que, devido à alta sensibilidade obtida com este novo sistema de detecção por absorção atômica e à presença de impurezas do material que constitui o filamento, os sinais transientes não retornaram à linha de base. Na determinação de traços de $\mathrm{Al}$ e $\mathrm{Cr}$ numa solução digerida do filamento, usando ETAAS com forno de grafite, foram encontra$\operatorname{dos} 5,9 \pm 0,3 \mu \mathrm{g} \mathrm{Al} \mathrm{g}^{-1}$ e 1,1 $\pm 0,1 \mu \mathrm{g} \mathrm{Cr} \mathrm{g}^{-1}$, mostrando realmente que o filamento empregado apresenta impurezas, o que pode comprometer os "brancos" durante as análises por ETAW-AAS e fornecer altos RSD's em determinações nas baixas concentrações analisadas. Apesar de não ser freqüente a referência da presença de impurezas no filamento, Sanford et al. ${ }^{52}$ observaram que o molibdênio também pode estar presente, afetando o resultado da análise. Se este tipo de efeito ocorrer com frequiência, será necessário a fabricação de 
Tabela 5. Figuras de méritos obtidos na determinação de $\mathrm{Al}$ e $\mathrm{Cr}$ em amostras de sangue, grafite e dióxido de titânio empregando laser de diodo em ETAW-AAS ${ }^{56}$

\begin{tabular}{|c|c|c|c|c|c|}
\hline \multirow[t]{2}{*}{ Analito } & \multirow{2}{*}{$\mathrm{LD}\left(\mathrm{ng} \mathrm{mL}^{-1}\right)$} & \multirow[t]{2}{*}{ matriz } & \multirow[t]{2}{*}{$\operatorname{RSD}(\%)$} & \multicolumn{2}{|c|}{ Resultado das análises } \\
\hline & & & & $\mathrm{V}_{\mathrm{M}}\left(\mu \mathrm{g} \mathrm{g}^{-1}\right)$ & $\mathrm{V}_{\mathrm{R}}\left(\mu \mathrm{g} \mathrm{g}^{-1}\right)$ \\
\hline \multirow{3}{*}{ Al } & \multirow{3}{*}{0,9} & Sangue & 9,1 & $16,4 \pm 1,5$ & $16,0 \pm 3,0$ \\
\hline & & Grafite & 19,2 & $5,2 \pm 1,0$ & $5,0 \pm 0,7$ \\
\hline & & $\mathrm{TiO}_{2}$ & 10,4 & $4,8 \pm 0,5$ & $5,1 \pm 0,3$ \\
\hline \multirow{3}{*}{$\mathrm{Cr}$} & \multirow{3}{*}{0,03} & Sangue & 16,9 & $1,42 \pm 0,24$ & $1,6 \pm 0,3$ \\
\hline & & Grafite & 16,6 & $0,60 \pm 0,10$ & $0,70 \pm 0,10$ \\
\hline & & $\mathrm{TiO}_{2}$ & 10,0 & $0,10 \pm 0,01$ & $0,11 \pm 0,01$ \\
\hline
\end{tabular}

$\mathrm{LD}=$ limite de detecção; $\mathrm{RSD}=$ desvio padrão relativo; $\mathrm{V}_{\mathrm{M}}=$ valor medido; $\mathrm{V}_{\mathrm{R}}=$ valor de referência

filamentos direcionados para o sistema ETAW-AAS, o que pode afetar uma das principais caraterísticas desta técnica, o baixo custo.

Segundo Welz ${ }^{3}$, a substituição das lâmpadas de cátodo oco e EDL pelo laser de diodo é uma questão de tempo, pois este laser de diodo semicondutor é do mesmo tipo que os fabricados em grande escala para aparelhos de som com CD ("compact disc players"), sistemas óticos de armazenamento de dados, impressora a laser e equipamentos de telecomunicação, além de ser barato, seguro, fácil de operar e com uma longa vida útil. É um sistema extremamente estável, não só em termos de comprimento de onda, mas também quanto à intensidade da radiação, possibilitando a determinação de não metais, tais como halogêneos e gases nobres, por espectrometria de absorção atômica.

Uma das limitações para a utilização do laser de diodo, atualmente, é o número de espécies que podem ser determinadas, em função da sua faixa de comprimento de onda. Entretanto, de acordo com Hou and Jones ${ }^{57}$ e com a empresa que fabrica o equipamento ${ }^{53}$ esse número, que hoje cobre cerca de 50 elementos, tende a crescer.

O resultado do uso do laser de diodo na AAS é apresentado pela empresa LaserSpec Analytik ${ }^{58}$, que comercializa equipamentos com esta nova tecnologia, destacando as seguintes vantagens: obtenção de menores LD; menor tamanho do equipamento; correção de fundo; capacidade de análise multielementar e capacidade de observar variações de até $10^{-5} \mathrm{~A} \mathrm{~s}^{-1}$.

Com base nos resultados apresentados na literatura, quanto ao emprego de ETAW-AAS para determinação de baixas concentrações de elementos, de um modo geral, a técnica vem se mostrando como um complemento ao forno de grafite em ETAAS nos equipamentos atuais. Porém, o estudo com o filamento de tungstênio leva ao desenvolvimento de equipamentos portáteis e dedicados.

Talvez com este novo equipamento de laser de diodo, o filamento tenha uma vantagem comparativamente aos tubos de grafite, que é a sua alta velocidade de aquecimento. Ao invés de se ter uma única temperatura de atomização em análise multielementar, poderia ser aplicada uma rampa de atomização, onde diferenças de até $1000{ }^{\circ} \mathrm{C}$ poderiam ser "varridas" em poucos segundos atingindo, dessa maneira, temperaturas ótimas de atomização para um grande número de elementos no mesmo programa de aquecimento do atomizador, enquanto nos espectrômetros atuais de análise multielementar existe esta limitação.

\section{OUTRAS APLICAÇÕES}

Outros trabalhos apresentam com sucesso a aplicação da ETAWAAS na determinação de baixas concentrações de elementos. Havesov et al. ${ }^{59}$ realizaram a determinação de metais alcalinos e alcalino-terrosos, que foram quantificados em amostras de paratungstato de amônio. Os LD's ficaram entre 0,02 e 1,6 ng mL ${ }^{-1}$. Em outro trabalho, o mesmo grupo $^{60}$ determinou $\mathrm{As}, \mathrm{Sb}$ e $\mathrm{Sn}$ em amostras de ouro puro, após a separação da matriz com hidrazina. Como a determinação com forno de grafite apresenta sérias limitações, provocadas pela alta concentração de cloreto, podem ocorrer severas interferências na etapa de atomização. O uso do filamento de tungstênio mostrou resultados comparáveis aos do forno de grafite, sem este inconveniente.

Giné et al. ${ }^{7}$ determinaram cádmio em materiais biológicos por ETAW-AAS, onde somente $10 \mu \mathrm{L}$ da amostra eram depositados sobre o filamento e o programa de temperatura tempo era de somente 41 s. O RSD foi menor que $3 \%$, a $\mathrm{m}_{0}$ foi de $0,5 \mathrm{pg}$ e os resultados de concentração foram concordantes para os diferentes materiais biológicos certificados, os quais foram digeridos em ácido nítrico.

\section{CONCLUSÕES}

De um modo geral, pode-se observar pelos trabalhos que procuram desenvolver novos instrumentos, que o emprego de ETAW-AAS parece não estar voltado a competir diretamente com o forno de grafite, mas sim em se firmar como uma técnica complementar à ETAAS, para fabricação de equipamentos portáteis e direcionados à aplicações específicas.

O preparo da amostra é fundamental para o sucesso da análise nos espectrômetros atuais, uma vez que a limitação do uso de filamento é tratar-se de um sistema não isotérmico, no qual matrizes mais complexas tornam as interferências mais acentuadas. Talvez essa seja a maior limitação para a popularização da técnica e somente o fato de apresentar baixo custo não é suficiente para justificar seu uso. É necessário tornar a técnica mais robusta e dois pontos são fundamentais para isso: contornar o problema de isotermicidade e reduzir a vazão do gás ou adicionar a parada de gás na etapa de atomização.

A substituição de filamentos de $150 \mathrm{~W}$ pelos de $250 \mathrm{~W}$ implicam numa maior área superficial, o que significa que uma maior quantidade de amostra pode ser introduzida no sistema. Com isso, melhores limites de detecção podem ser alcançados. Por outro lado, isso aumenta o consumo de energia elétrica.

A vantagem do emprego de filamento para ETAAS é a possibilidade do desenvolvimento de equipamentos portáteis, que poderiam ser comercializados com baixo custo e direcionados à certas aplicações, como por exemplo, para a análise de $\mathrm{Pb}$ em amostras de sangue para laboratórios de análises clínicas, entre outros.

O emprego de filamentos para ETAAS provavelmente vai se tornar mais atraente com a nova tecnologia de laser de diodo, pois o feixe de radiação apresenta um diâmetro de $1,2 \mathrm{~mm}$. Isso permite que a leitura de absorção atômica do analito seja realizada em uma região bastante próxima ao filamento, onde o problema de isotermicidade não é tão grave, ou até mesmo desprezível. Considerando-se o alto poder de detecção do laser, além da possibilidade de obter uma análise 
multielementar e uma rampa de atomização no filamento, a qual fornece temperaturas ótimas de atomização para vários elementos em uma única etapa de aquecimento, a ETAW-AAS com fonte de laser de diodo, poderá tornar-se uma técnica independente e deixar de ser somente uma alternativa para ETAAS, uma vez que pode apresentar vantagens reais frente ao uso de tubos de grafite.

As figuras de mérito aqui discutidas também mostram a potencialidade desta técnica. Os limites de detecção para ETAWAAS são semelhantes ou até melhores do que os obtidos com ETAAS com forno de grafite e os RSD's normalmente são baixos, o que mostra a reprodutibilidade do sistema. Os resultados obtidos para a concentração de diferentes espécies químicas mostraram boa concordância com os valores esperados. Entretanto, é necessário ter em mente que todos esses parâmetros variam de acordo com a configuração do sistema nos diferentes trabalhos, a capacidade do analista em otimizar o sistema e, principalmente, o procedimento utilizado para o preparo das amostras.

A possibilidade de determinação de um maior número de elementos por AAS, em função da utilização do laser de diodo, e o desenvolvimento da cela eletrotérmica para a determinação de espécies na forma gasosa mostram a versatilidade da técnica de ETAWAAS. Assim, é razoável supor que ela poderá ser amplamente utilizada em análises de rotinas em um futuro próximo.

\section{AGRADECIMENTOS}

Os autores gostariam de expressar seus agradecimentos aos assessores deste trabalho e a J. C. J. Silva, pelas sugestões. A. S. Ribeiro agradece ao CNPq pela bolsa de Doutorado.

\section{REFERÊNCIAS}

1. Walsh, A.; Spectrochim. Acta, Part B 1955, 7, 108.

2. L'vov, B. V.; Spectrochim. Acta, Part B 1961, 17, 761.

3. Welz, B.; Spectrochim. Acta, Part B 1999, 54, 2081.

4. L'vov, B. V.; Spectrochim. Acta, Part B 1984, 39, 149.

5. Berndt, H.; Schaldach, G.; J. Anal. At. Spectrom. 1998, 3, 709

6. Williams, M.; Piepmeier, E. H.; Anal. Chem. 1972, 44, 1342.

7. Giné, M. F.; Krug, F. J.; Sass, V. A.; Reis, B. F.; Nóbrega, J. A.; Berndt, H.; J. Anal. At. Spectrom. 1993, 8, 243.

8. Krug, F. J.; Silva, M. M.; Oliveira, P. V.; Nóbrega, J. A.; Spectrochim. Acta Part B 1995, 50, 1469.

9. Oliveira, P.V.; Catanho, M.; Nóbrega, J.A.; Luccas, P.O.; Quim. Nova 2000 23,706 .

10. Nóbrega, J. A.; Silva, M. M.; Oliveira, P. V.; Krug, F. J.; Baccan, N.; Quim. Nova 1995, 18, 555.

11. Winefordner, J.D.; Bratzel, M.P.; Dagnall, R.M.; Anal. Chim. Acta 1969,48 197.

12. Goode, S.R.; Montaser, A.; Crouch, S.R.; Appl. Spectrosc. 1973, 27, 355.

13. Crouch, S.R.; Montaser, A.; Anal. Chem. 1975, 47, 38.

14. Lund, W.; Larsen, B.V.; Gundersen, N.; Anal. Chim. Acta 1976, 81, 319.

15. Maruta, T.; Takeuchi, T.; Anal. Chim. Acta 1973, 66, 5.

16. Agget, J.; Analyst 1983, 108, 808.

17. Chauvin, J.V.; Newton, M.P.; Davis, D.G.; Anal. Chim. Acta 1973, 65, 291

18. Chauvin, J.V.; P.; Davis, D.G.; Hargis, L.C.; Anal. Lett. 1992, 25, 137.

19. Reid, R.D.; Piepmeier, E.H.; Anal. Chem. 1976, 48, 338.

20. Lund, W.; Larsen, B.V.; Anal. Chim. Acta 1974, 70, 299.

21. Lund, W.; Larsen, B.V.; Anal. Chim. Acta 1974, 72, 57.

22. Sychra, V.; Vysckocilová, O.; Kolihova, D.; Puschel, P.; Anal. Chim. Acta 1979, 105, 271 .
23. Muzgin, V.N.; Atnashev, Yu B.; Korepanov, V. E.; Pupyshev, A. A.; Talanta 1987, 34, 197.

24. Chakrabarty, C.L.; Delgado, A.H.; Chang, S.B.; Falk, H.; Huton, T.J.; Runde, G.; Sychra, V.; Dolezal, J.; Spectrochim. Acta 1986, 41 B, 1075.

25. Chakrabarty, C.L.; Delgado, A.H.; Chang, S.B.; Falk, H.; Sychra, V.; Dolezal, J.; Spectrochim. Acta 1989, 44 B, 209.

26. Santos, D.M.; Luccas, P.O.; Nóbrega, J.A.; Cavalheiro, E.T.G.; Thermochim. Acta 2000, 362, 161.

27. Bruhn, C.G.; Ambiado, F.E.; Cid, H.J.; Woerner, R.; Tapia, J.; Garcia, R.; Anal. Chim. Acta 1995, 306183.

28. Silva, M.M.; Silva, R.B.; Krug, F.J.; Nóbrega, J.A.; Berndt; H.; J. Anal. At. Spectrom. 1994, 9, 861

29. Parsons, P.J.; Qiao, H.; Aldous, K. M.; Mills, E.; Slavin, W.; Spectrochim. Acta, Part B 1995, 50, 1475.

30. Salido, A.; Sanford, C.L.; Jones, B.T.; Spectrochim. Acta, Part B 1999, 54, 1167.

31. Zhou, Y.; Parsons, P.J.; Aldous, K.M.; Brockman, P.; Slavin, W.; J. Anal. Atom. Spectrom. 2001, 16, 82.

32. Bruhn, C.G.; Ambiado, F. E.; Cid, H.J.; Woerner, R.; Tapia, J.; Garcia, R.; Quim. Anal. 1996, 15, 191

33. Luccas, P.O. ; Nóbrega, J.A.; Oliveira, P.V.; Krug, F.J.; Talanta 1999, 48, 695.

34. Ostrega, P.; Bulska, E.; Hulanicki, A.; Chem. Anal.(Warsaw) 1993, $38,779$.

35. Knochen, M.; Saritsky, E.; Doi, I.; Quim. Anal. 1996, 15, 184.

36. Bruhn, C.G.; Neira, J.Y.; Valenzuela, G.D.; Nóbrega, J.A.; J. Anal. At. Spectrom. 1998, 13, 29.

37. Oliveira, P.V.; Krug, F.J., Silva, M.M.; Nóbrega, J.A.; Queiroz, Z.F.; Rocha, F.R.P.; J. Braz. Chem. Soc. 2000, 11,136.

38. Barbosa Jr., F.; Krug, F.J.; Lima, E.C.; Spectrochim. Acta, Part B 1999, $54,1155$.

39. Silva, M.M.; Krug, F.J.; Oliveira, P.V.; Nóbrega, J.A.; Reis, B.F.; Penteado, D.A.G.; M.; Spectrochim. Acta 1996, 51 B, 1925.

40. Silva, M.M.; Arruda, M.A.Z.; Krug, F.J.; Oliveira, P.V.; Queiroz, Z.F.; Gallego, M.; Valcárcel, M.; Anal. Chim. Acta 1998, 368, 255.

41. Lima, E.C.; Krug, F.J.; Nóbrega, J.A.;. Nogueira, A.R.A.; Talanta 1998, $47,613$.

42. Lopes, G.S.; Nogueira, A.R.A.; Oliveira, P.V.; Nóbrega, J.A.; Anal. Sci. 1999, 15,165

43. Silva, J.C.J.; Garcia, E.E.; Nóbrega, J.A.; Nogueira, A.R.A.; Talanta 2001, $55,847$.

44. Ediger, R.D.; Atom. Absorpt. Newslett. 1975,14, 127.

45. Schlemmer, G.; Welz, B.; Spectrochim. Acta, Part B 1986, 41, 1157.

46. Bruhn, C.G.; Neira, J.Y.; Guzmán, M.I.; Darder, M.M.; Nóbrega, J.A.; Fresenius' J. Anal. Chem. 1999, 364, 273.

47. Bruhn, C.G.; San Francisco, J.Y.; Neira, J.Y.; Nóbrega, J.A.; Talanta 1999, $50,967$.

48. Bruhn, C.G.; Neira, J.Y.; Valenzuela, G.D.; Nóbrega, J.A.; Talanta 1999, $48,537$.

49. Hou, X.; Levine, K.E.; Salido, A.; Jones, B.T.; Ezer, M.; El Wood, S.; Simeonsson, J.B.; Anal. Sci. 2001, 17, 175.

50. Wagner, K.A.; Levine, K.E.; Jones, B.T.; Spectrochim. Acta, Part B 1998, $53,1507$.

51. Salido, A.; Jones, B.T.; Talanta 1999, 50, 649.

52. Sanford, C.L.; Thomas, S.E.; Jones, B.T.; Appl. Spectrosc. 1996, $50,174$.

53. Batchelor, J.D.; Thomas, S.E.; Jones, B.T.; Appl. Spectrosc. 1998, 52, 1086.

54. Neira, J.Y.; Valenzuela, G.D.; Vega, J.; Moya, J.; Bruhn, C.G.; Nóbrega, J.A.; Quim. Nova 1998, 21, 490 .

55. Ribeiro, A.S.; Moretto, A.L.; Arruda, M.A.Z.; Cadore, S.; $8^{\text {th }}$ International Conference on Flow Analysis, Warsaw, Poland, 2000.

56. Krivan, V.; Barth, P.; Schnürer-Patschan, C.; Anal. Chem. 1998, 70, 3525.

57. Hou, X.; Jones, B.T.; Microchem. J. 2000, 66,115.

58. http://www.laserspec.de/, acessada em Dezembro, 2000.

59. Havesov, I.; Ivanova, E.; Berndt, H.; Schaldach, G.; Fresenius' J. Anal. Chem. 1990, 336, 484.

60. Ivanova, E.; Havesov, I.; Berndt, H.; Schaldach, G.; Fresenius' J. Anal. Chem. 1990, 336, 320 